\title{
Inhibition of Escherichia Coli, Pseudomonas Aeruginosa, Staphylococcus Aureus and Enterococcus Feacalis through Malus Domestica Extracts to Eliminate Food Borne Illness
}

\author{
Hina Nazar', Umar Farooq ${ }^{2 *}$, Kashif Akram $^{3}$, Afshan Shafi' ${ }^{2}$, Zafar Hayat ${ }^{4}$, Madhura A \\ Jayasinghe $^{5}$ and Samra Naseem ${ }^{6}$ \\ ${ }^{1}$ Institute of Food Science and Nutrition, University of Sargodha, Pakistan \\ ${ }^{2}$ Department of Food Science and Technology, MNS University of Agriculture, Pakistan
}

${ }^{3}$ Department of Food Science and Nutrition, Cholistan University of Veterinary and Animal Sciences, Pakistan

${ }^{4}$ Department of Animal Sciences, University of Veterinary \& Animal Sciences, Pakistan

${ }^{5}$ Department of Food Science and Technology, University of Sri Jayewardenepura, Sri Lanka

${ }^{6}$ Department of Math and Stat, MNS University of Agriculture Multan, Pakistan

*Corresponding author: Umar Farooq, Department of Food Science and Technology, MNS University of Agriculture, Multan, Pakistan.

To Cite This Article: Umar Farooq. Inhibition of Escherichia Coli, Pseudomonas Aeruginosa, Staphylococcus Aureus and Enterococcus Feacalis through Malus Domestica Extracts to Eliminate Food Borne Illness. Am J Biomed Sci \& Res. 2019 - 3(5). AJBSR.MS.ID.000701.

DOI: 10.34297/AJBSR.2019.03.000701

Received: June 17, 2019 | Published: June 28, 2019

\begin{abstract}
The present study was designed to evaluate the antibacterial activity of aqueous extracts of Malus domestica (peel and pomace) against foodborne pathogens (Escherichia coli, Pseudomonas aeruginosa, Staphylococcus aureus and Enterococcus feacalis). Extraction conditions (temperature and time) were optimized to obtain maximum yield by using response surface methodology. Antibacterial potentials of the extracts were examined through disc inhibition zone technique and the results were compared with commercial antibiotic. Results indicated that maximum antibacterial activity was shown by peel extract against Staphylococcus aureus with average zone of inhibition $19.25 \pm 0.89 \mathrm{~mm}$ while pomace $12.75 \pm 0.71 \mathrm{~mm}$. The antibacterial activities of peel extract were comparable with commercial antibiotic $(20.13 \pm 0.83 \mathrm{~mm})$. Escherichia coli were appeared to be the most resistant with inhibition induced by the extracts of peel $15.00 \pm 1.07 \mathrm{~mm}$ and pomace $11.50 \pm 0.53 \mathrm{~mm}$.
\end{abstract}

Keywords: Food borne pathogens; Food safety; Food borne illness; Malus domestica; Extract; Antibacterial activity

\section{Introduction}

Pathogenic microbial agents such as bacteria, fungi and viruses are major threats to food safety as well as community health [1]. These microorganisms cause number of diseases, such as Gastrointestinal tract infection, diarrhoea, nausea, intestinal disorders, abdominal bloating, allergies and inflammatory disorders. Use of antibiotics have shown the cure and suppression of diseases but it also lead to increase resistance as well as expansion of strains [2]. This situation has necessitated a search for natural antimicrobial agent against pathogenic microbes to control such disorders and to ensure food safety. Fruits phytochemicals and their extracts with identified antimicrobial activities have great importance in the treatment of many infectious diseases [3]. Recent study has exposed that peel and seed of many fruits like apple peel, grape peels and seeds [4], pomegranate peel [5], mango seed kernel [6] and wampee peel [7] may possibly have antimicrobial property. All components of plants separately or in combination show antimicrobial activity and antimicrobial agents can be found in any part of plant as in stalks, bark, leaves, roots, fruits, flowers, seeds, pods, latex, stems, fruit rind and hull [8]. Apple fruit and its extract have been used as medicine for prevention and treatment of different diseases [9]. 
Malus domistica (Apple) is the pomaceous produce of apple tree, in family rose (Rosaceae) and species Malus domestica [10]. Biological assays showed that apple polyphenols have a wide range of pharmacological effects, such as anti-bacterial [11], antiviral [12], antioxidant activity [13], and the inhibition of colon carcinogenesis [14]. There is huge amount of apple by-products (peel and pomace) are generated as a result of processing, which is an abundant source of phytochemicals and these kinds of bio resources could be used for extraction of fruit phenolics [15]. These compounds offer very strong facts of antimicrobials uniqueness. Thus, the recovery of apple polyphenols from pomace as an excellent healthcare product is another important biotechnological application [16].

Various studies have revealed that apple extracts exhibit antimicrobial activity [17]. Malaviya and Mishra [18] evaluated the alcoholic and aqueous extracts of apple to check the antimicrobial activity against fungi and bacteria. Comparison of both extracts showed that the aqueous extracts of apple fruit demonstrated greater antimicrobial activity against Gram positive bacteria ( $B$. subtilis and $S$. aureus) as compared to Gram negative bacteria ( $P$. aeruginosa and E. coli). Muthusamy and Ranasinghe [19] have studied the antimicrobial activity of selected apple phenolics (chlorogenic acid, catechin and phloridzin). These three tested phenolic compounds suppressed the growth of E. coli (Gram negative bacteria) and Listeria innocua (Gram positive bacteria), the two pathogenic bacteria. Jelodarian [20] also evaluated the antimicrobial activity of apple fruit. But there is no comprehensive research about the antibacterial activity of apple by-products (peel ad pomace).

By considering the significant functionality of apple peel and pomace, present study was designed to optimize the extraction conditions by using response surface methodology and then to inhibit the food-borne pathogens (Escherichia coli, Pseudomonas aeruginosa, Staphylococcus aureus and Enterococcus feacalis) by the use of aqueous extracts of apple peel and pomace in comparison with commercially available antibiotics.

\section{Materials and Methods}

\section{Sample preparation}

Fresh apples were purchased from a local market of Sargodha of golden verity and were brought to the Food Microbiology Laboratory, Institute of Food science and Nutrition, University of Sargodha in plastic bags. The fruits were washed, dried and then peel was manually separated. The peels and pomace (after juice extraction) were dried in an oven (BINDER) at $55^{\circ} \mathrm{C}$ for 3 days. Then dried peels and pomace were powdered in a grinder (MOULINEX) and stored in plastic bags for next step of extraction.

\section{Extraction procedure}

Five gram of each dried and ground samples (pomace or peels) were weighed on a sensitive balance (SHIMADZU) and then transferred to two fifty millilitre conical flask. One hundred millilitre distilled water was added into flask and placed on hot plates (VELP SCIENTIFICA). Each conical flask mouth was covered with aluminium foil to avoid the excessive evaporation. The liquid extract was separated from solids by using muslin cloth. Then again it was filtered through Whatman No. 1 filter paper by using vacuum suction filtration assembly. The supernatant was then transferred to a rotary evaporator (HB DIGITAL, HEIDOLPH) at $60^{\circ} \mathrm{C}$ to evaporate the water under vacuum. Then the extract was dried in hot air oven at $60^{\circ} \mathrm{C}$ until constant weight. All samples were extracted in duplicates.

\section{Experimental design}

Firstly, screening experiments were conducted through a single factor experimental design. Independent factors, such as temperature and time were investigated to find most important independent factors and their respective ranges to maximize percentage extraction yield (response variable). Orthogonal experimental design was used employing significant independent factors for the optimization through response surface methodology (RSM).

\section{Single factor experiments}

Before using RSM, the initial experiments were carried out to select the significant variables in extract recovery as well as the experimental range for independent factors. In single factor analysis, extraction temperature and extraction time were found to be the most important factors to obtain maximum recovery. Each sample was extracted with water at $30,50,70$, and $90^{\circ} \mathrm{C}$ for $45 \mathrm{~min}$ and at $60^{\circ} \mathrm{C}$ for $15,30,45$ and 60 minutes. The liquid solid ratio $(5 \mathrm{~g} / 100 \mathrm{ml})$ and particle size (40 mesh) was kept constant.

\section{Response surface modelling}

\begin{tabular}{|c|c|c|c|c|c|}
\hline \multicolumn{2}{|c|}{ Table 1: Independent variables and their levels for orthogonal design. } \\
\hline \multicolumn{4}{|c|}{ Levels } \\
\hline \multirow{3}{*}{ Independent variable } & Symbols & $\mathbf{- 1}$ & $\mathbf{0}$ & $\mathbf{1}$ \\
\hline \multirow{3}{*}{ Peel } & Temp $\left({ }^{\circ} \mathrm{C}\right)$ & $\mathrm{X}_{1}$ & 50 & 70 & 90 \\
\cline { 2 - 6 } & $\mathrm{Time}(\mathrm{min})$ & $\mathrm{X}_{2}$ & 15 & 30 & 45 \\
\hline \multirow{3}{*}{ pomace } & $\mathrm{Temp}\left({ }^{\circ} \mathrm{C}\right)$ & $\mathrm{X}_{1}$ & 50 & 70 & 90 \\
\cline { 2 - 6 } & $\mathrm{Time}(\mathrm{min})$ & $\mathrm{X}_{2}$ & 15 & 30 & 45 \\
\hline
\end{tabular}

Table 2: Orthogonal design with two factors and three levels and their extract recovery from peel.

\begin{tabular}{|c|c|c|c|}
\hline Run & Temp $\left({ }^{\circ} \mathrm{C}\right) \mathrm{X}_{1}$ & Time $(\mathrm{min}) \mathrm{X}_{2}$ & Yield (\%) ( $\left.\mathrm{Y}_{1}\right)$ \\
\hline 1 & $50(-1)$ & $15(-1)$ & $23.75 \pm 0.35$ \\
\hline 2 & $90(1)$ & $45(1)$ & $27.1 \pm 0.14$ \\
\hline 3 & $50(-1)$ & $30(0)$ & $25.3 \pm 0.28$ \\
\hline 4 & $90(1)$ & $30(0)$ & $27.5 \pm 0.00$ \\
\hline 5 & $70(0)$ & $15(-1)$ & $24.35 \pm 0.21$ \\
\hline 6 & $70(0)$ & $45(1)$ & $27.75 \pm 0.35$ \\
\hline 7 & $70(0)$ & $30(0)$ & $28.00 \pm 0.00$ \\
\hline 8 & $70(0)$ & $30(0)$ & $28.15 \pm 0.21$ \\
\hline 9 & $70(0)$ & $30(0)$ & $27.55 \pm 0.07$ \\
\hline
\end{tabular}

Orthogonal test design (Table 1) was employed for optimization of extraction conditions. Two factors (coded and uncoded value) and three levels were examined for the optimum combination of extraction variables based on the highest extraction yield of samples in initial experiment. Extraction yield was taken as response Y with 
standard deviation (Table 2). The variables Xi were implicit as xi based on Equation (1):

$$
\mathrm{Xi}=(\mathrm{Xi}-\mathrm{X} \mathrm{i}) / \Delta \mathrm{Xi}
$$

Where xi was the coded value $(-1,0,+1$,) of an independent variable, was the real value of an independent variable at the centre point, and $\Delta \mathrm{Xi}$ was the step change value.

\section{Statistical analysis}

All data was replicated thrice, and results were averaged. Design expert SAS 9.2 was used for optimization. Single factor experiments were presented on Excel sheet (Microsoft office Enterprise 2007). Multiple linear regression analysis was conducted by the statistical software (SAS 9.2). Experimental data were fitted into a secondorder polynomial model as shown in equation (2):

$$
y=\beta o+\sum_{i=1}^{k} \beta i \mathrm{X} i+\sum_{i=1}^{k} \beta i i \mathrm{X} 2 i+\sum_{\substack{i=1 \\ i<j}}^{k-1} \sum_{j=2}^{k} \beta i j \mathrm{X} i \mathrm{Xj} \text { (2) }
$$

where $\mathrm{Xi}$ and $\mathrm{Xj}$ were the independent variables effecting the responses $\mathrm{Y} ; \beta 0, \beta \mathrm{i}, \beta \mathrm{i}, \beta \mathrm{ij}$ were the regression coefficients of variables for intercept, linear, quadratic and interaction terms, respectively; $\mathrm{k}$ was the number of variables $(\mathrm{k}=2)$. The quality of fit of the polynomial model was articulated by the coefficient of determination R2, and the statistical significances were probed by determining the F-value at a probability (p) at $0.001,0.01$, or 0.05 .

\section{Microorganisms and culture media}

The food-borne pathogens Escherichia coli, Pseudomonas aeruginosa, Staphylococcus aureus, and Enterococcus feacalis were obtained from Food Microbiology Laboratory, Institute of Food Science and Nutrition, University of Sargodha, Sargodha. These cultures were maintained on nutrient agar plate by continuous subculturing after 10 - 15 days.

\section{Assessment of antimicrobial activity}

The antimicrobial effects of the apple extracts were evaluated against isolated strains of pathogens by "disc diffusion method" as suggested by Sadeghian et al. [21] with some modifications.

\section{Results and discussion}

\section{Extraction}

The preliminary extraction of these compounds was performed at various temperatures and times to observe significant variable and range for maximum recovery of the extracts.

\section{Influence of temperature on recovery of water-soluble compounds}

Conventional extraction and concentration of apple extract (peel and pomace) was done at temperature ranging from $30^{\circ} \mathrm{C}$ to $90^{\circ} \mathrm{C}$ for 45 minutes (fixed). (Figure $1 \mathrm{a}$ ) indicated that the recovery of soluble compounds was increased with the increment in temperature up to $70^{\circ} \mathrm{C}$ and then decline in percent recovery of the extract was observed. Maximum recovery from peel was obtained at $70^{\circ} \mathrm{C}$ followed by $90^{\circ} \mathrm{C}$ and $50^{\circ} \mathrm{C}$, which was $16.33,14.67$ and $12.67 \%$, respectively. The results were in accordance with the findings of Wisaam et al. (2012) who observed $18.00 \%$ yield of water-soluble extracts of dried fruit peel at $50^{\circ} \mathrm{C}$.

Similarly, the maximum recovery of extract from apple pomace was observed at $70^{\circ} \mathrm{C}$ with mean percent recovery of $16.67 \%$ (Figure 1a). Least recovery was obtained at temperature $30^{\circ} \mathrm{C}$ with mean percent recovery of $3.67 \%$ (Figure 1b). Some researchers had also observed similar results while working on various fruit extracts and reported that the extraction yield was increased with temperature and was maximum at $60^{\circ} \mathrm{C}$ [22-24] and $50^{\circ} \mathrm{C}$ [25].

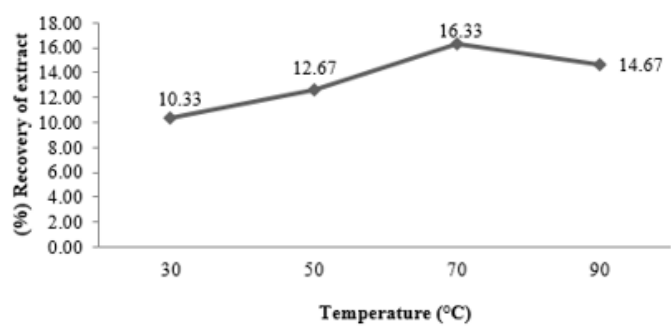

(a)

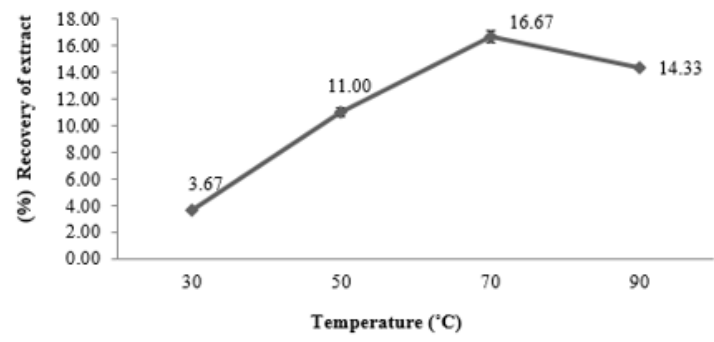

(b)

Figure 1: Influence of temperature $\left({ }^{\circ} \mathrm{C}\right)$ on the extraction of water-soluble compounds from apple peel (a) and pomace (b). 


\section{Influence of time on recovery of water-soluble compounds}

The results depicted in (Figure $2 \mathrm{a}$ ) revealed that the extraction of water-soluble compounds from apple peel and pomace was gradually increased with increment in time up to 30 minutes and after this there was a decline in percent recovery of the extracts at $60^{\circ} \mathrm{C}$ temperature (fixed). The maximum recovery of $18.67 \%$ and $22.17 \%$ was obtained for peel and pomace. The extraction rate was highly dependent on time of treatment and it was observed that by increasing the time, the extraction yield was also increased but after 30 minutes there was a decline in percent recovery of the extract. The results were similar to the findings of Wissam et al. [26], who also reported reduced extraction rate of aqueous fruit peel extracts after $30 \mathrm{~min}$ of treatment. This decline in recovery might be due to degradation of polyphenols and proanthocyanins (components of extract) (Figure 2b).

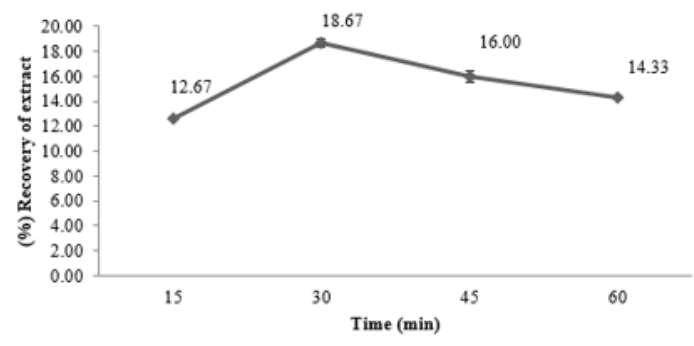

(a)

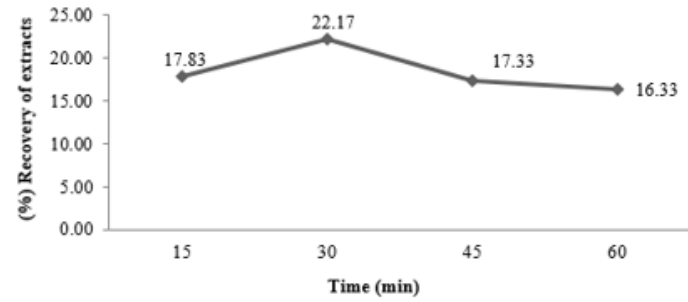

(b)

Figure 2: Influence of time ( $\mathrm{min}$ ) on the extraction of water-soluble compounds from apple peel (a) and pomace (b).

\section{Optimization of extraction conditions}

To assess the effects of two independent variables including extraction time $\left(X_{1}\right)$ and temperature $\left(X_{2}\right)$, response surface methodology was employed for extraction of water-soluble compounds from apple peel and pomace. For this purpose, on the basis of single factor results, the temperature conditions being selected were $70^{\circ} \mathrm{C}$ as central point and the upper and lower levels being chosen were $90^{\circ} \mathrm{C}$ and $50^{\circ} \mathrm{C}$, respectively. Similarly, depending upon the central point for time period ( 30 minutes), 45 minutes and 15 minutes were taken as upper and lower level of time factor for the preparation of various combinations of time and temperature through RSM. Similar temperature and time combinations were also used by some previous scientists for extraction of watersoluble compounds from fruits or parts of the fruits. Dent et al. [23] performed extraction for a period of 30,60 and 90 minutes at $60^{\circ} \mathrm{C}$ and $90^{\circ} \mathrm{C}$.

(Tables $1 \& 2$ ) present the running variables and mean percent recovery with standard deviation (Y). By applying multiple regression analysis on the experimental data, the model for the response variable could be expressed by the following quadratic polynomial equation in the form of coded values.
Predictive Model for Yeild (peel) $=3.0625+0.47375 \times \mathrm{X} 1+$ 0.3775 x X2 -0.00375 x X1 x X1 + 0.002917 x X1 x X2 - 0.008222 x $\underline{\mathrm{X} 2 \times \mathrm{X} 2}$

Predictive Model for Yeild (pomace) $=5.46875+$ 0.405417 x X1+0.186389 x X2 - 0.002479 x X1 x X1+0.000306 x $\underline{\mathrm{X} 1 \times \mathrm{X} 2-0.002852 \times \mathrm{X} 2 \times \mathrm{X} 2}$

The result of statistical analysis (ANOVA) regarding effect of time and temperature on mean percent recovery of water-soluble compounds showed that the combine effect of time and temperature on extraction from peel and pomace was non-significant. While the combination of temperature and temperature and time and time showed significant results.

\section{Analysis of response surfaces}

Three-dimensional response surface and two-dimensional contour plots are the graphical representations of regression equation and are very useful to judge the relationship between independent and dependent variables. Different shapes of the contour plots indicate whether the mutual interactions between the variables are significant or not. Circular contour plot means the interactions between the corresponding variables are negligible, 
while elliptical contour suggests the interactions between the corresponding variables are significant [27]. The effect of extraction time and temperature on recovery of water-soluble compounds from peel and pomace was illustrated in the three-dimensional response surfaces and 2-dimensional contour plots (Figure 3a-3d). Response surface revealed that the optimum extraction yield of apple extracts was observed at $70^{\circ} \mathrm{C}$ for 30 minutes of treatment with mean recovery of $27.9 \%$ of peel and $25.3 \%$ of pomace.
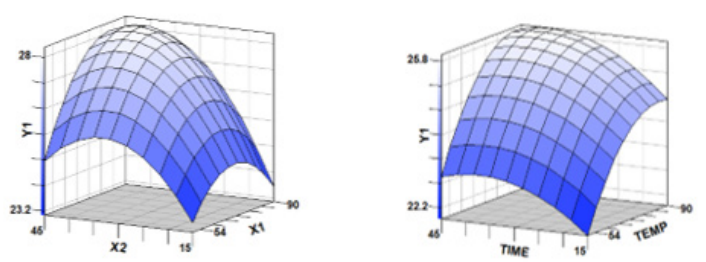

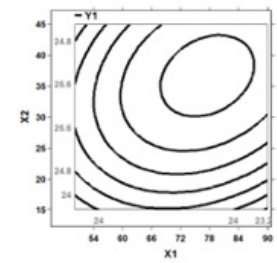

(c) (b)

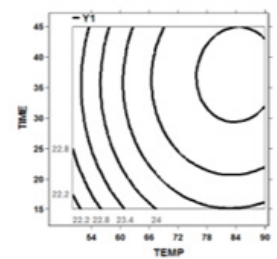

(d)

Figure 3: Response surface and Contour plot showing the effect of temperature $\left(\mathrm{X} 1,{ }^{\circ} \mathrm{C}\right)$ and time $(\mathrm{X} 2$, min) on recovery of water-soluble compounds from apple peel ( $a$ and $c$ ) and pomace ( $b$ and $d)$.

\section{Evaluation of antimicrobial activity of various extracts of apple}
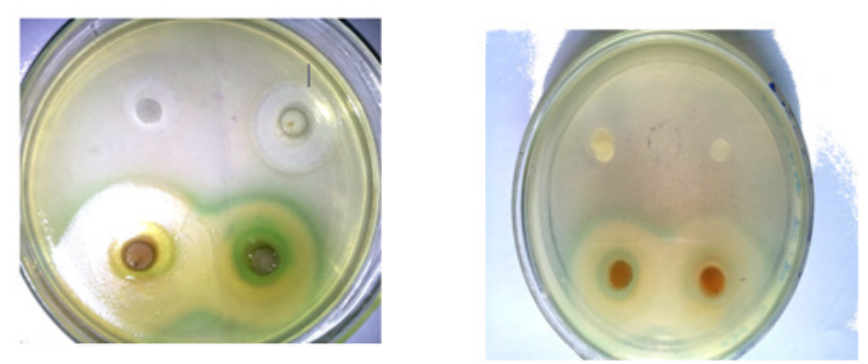

Figure 4: Antibiogram of antimicrobial activity of peel and pomace extracts and antibiotics.

The extracts obtained can potentially be used in the treatment of infectious diseases caused by microorganisms that are showing emergence of resistance to currently available antibiotics. The antimicrobial effects of the apple peel and pomace extracts were evaluated by disc diffusion method. In the present study, the antibacterial potential of aqueous extracts of apple peel and pomace were evaluated against different pathogens (E. coli, P. aeruginosa, S. aureus and E. feacalis) and also compared with a commercially available antibiotic (Figure 4). The results obtained so far are explained one by one as follow:

\begin{tabular}{|c|c|c|c|c|}
\hline \multicolumn{5}{|c|}{ Table 3: Average antibacterial activity of extracts and antibiotic. } \\
\hline Extract & E. coli & P. aeruginosa & S. aureus & E. feacilis \\
\hline Peel & $15.00 \pm 1.07$ & $13.50 \pm 1.20$ & $19.25 \pm 0.89$ & $17.63 \pm 1.06$ \\
\hline Pomace & $11.50 \pm 0.53$ & $9.05 \pm 0.71$ & $12.75 \pm 0.71$ & $14.00 \pm 1.07$ \\
\hline Antibiotic & $22.50 \pm 1.20$ & $19.00 \pm 0.76$ & $20.13 \pm 0.83$ & $19.50 \pm 0.53$ \\
\hline
\end{tabular}

Average values of zones of inhibition were presented in (Table $3)$.

The results revealed that the antimicrobial potential of apple extracts was more prominent against Gram's +ve bacteria. Kalmenson et al. [28] and Parikh et al. [29], who recommended that the Gram +ve bacteria are less resistant than that of Gram ve bacteria. The greater resistance of Gram's negative bacteria against plant extracts than Gram positive bacteria might be due to the differences in chemical composition and structure of cell wall of both types of microorganisms as described by Holley and Patel [30].

Escherichia coli (E. coli) and Pseudomonas aeruginosa ( $P$. aeruginosa) both are Gram negative food-borne pathogens with respect to their cell structure. The extracts showed reasonable/ significant antibacterial activity against E. coli as compared with 
antibiotic (ciprofloxacin). The results for antibacterial activity of apple extracts and antibiotic against E. coli are given in (Figure $5 a)$. The zone of inhibitions for antibiotic, peel extract and pomace extract were $22.50 \mathrm{~mm}, 15.00 \mathrm{~mm}$ and $11.50 \mathrm{~mm}$, respectively. Similarly, antibacterial activity of apple extracts and antibiotic against P. aeruginosa is given in (Figure 5b). The maximum inhibition zone against P. aeruginosa was observed in case of antibiotic followed by peel extract with mean inhibition zone of
$19.00 \mathrm{~mm}$ and $13.50 \mathrm{~mm}$, respectively and the minimum inhibition was observed in case of pomace extract with mean inhibition zone of $9.05 \mathrm{~mm}$. The results were closely related to the findings of Fratianni et al. [31] who observed $6 \mathrm{~mm}$ to $13 \mathrm{~mm}$ inhibitory zone of apple extracts against E. coli. Some other researchers also reported that the apple extract have $11 \mathrm{~mm}$ and $6 \mathrm{~mm}(0.6 \mathrm{~cm})$ inhibition zones against $\mathrm{P}$. aeruginosa $[18,20]$.
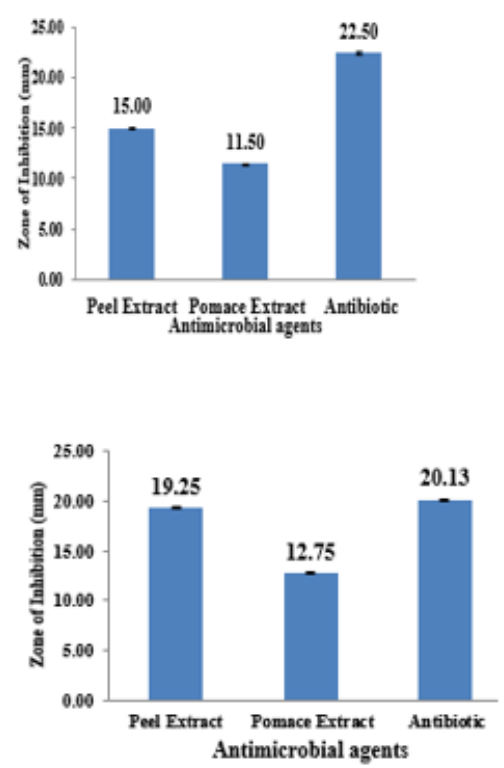

(c)
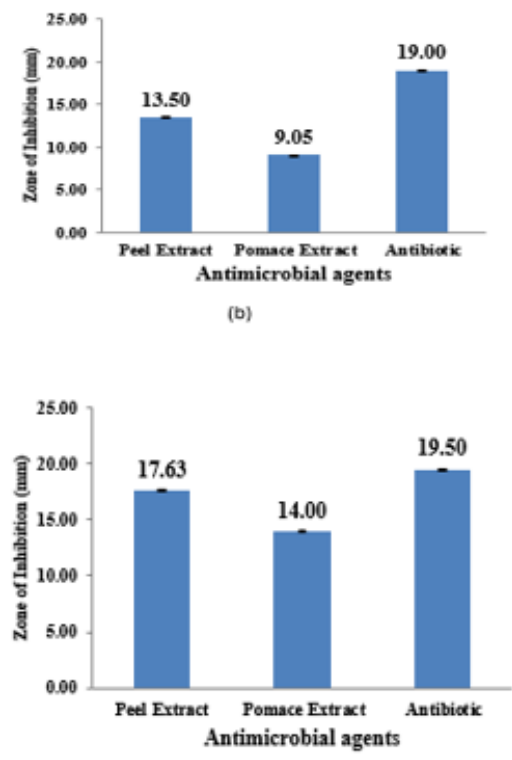

(d)

Figure 5: Antibacterial activity of apple extracts against Escherichia coli (a), Pseudomonas aeruginosa (b), Staphylococcus aureus (c) and Enterococcus faecalis (d)

The Gram's +ve bacteria selected for the experiment were Staphylococcus aureus (S. aurous) and Enterococcus feacalis (E. feacalis). The results of disc diffusion method against S. aurous and E. feacalis are given in (Figure $5 \mathrm{c} \& 5 \mathrm{~d}$ ). Inhibition zones of apple extracts and antibiotic against S. aurous are given in Fig. 5c. The zone of inhibitions for antibiotic, peel extract and pomace extract were $20.13 \mathrm{~mm}, 19.25 \mathrm{~mm}$ and $12.75 \mathrm{~mm}$, respectively. The maximum inhibition zone against $\mathrm{E}$. feacalis was observed in case of antibiotic followed by peel extract with mean inhibition zone of $19.50 \mathrm{~mm}$ and $17.63 \mathrm{~mm}$, respectively and the minimum inhibition was observed in case of pomace extract with mean inhibition zone of $14.00 \mathrm{~mm}$ as shown in (Figure $5 \mathrm{~d}$ ). The similar results were also observed by Malaviya and Mishra [18] and Alberto et al. [17], who reported that water extract of apple showed higher activity against Gram's positive bacteria (S. aureus and E. feacalis). The antimicrobial potential of the apple extracts could be related to the presence of various functional/bioactive compounds like phenolics [32]. The apple also contains various phytochemicals, which give precious properties to the apple with special reference to antimicrobial potential against different infectious diseases [33].

\section{Conclusions}

The results directed that extracts of apple peel and pomace possessed noteworthy antibacterial activity of clinical significance against the bacterial strains. All the extracts showed inhibition against these pathogens (Escherichia coli, Pseudomonas aeruginosa, Staphylococcus aureus, and Enterococcus feacalis). Apple peel has maximum inhibition (19.25 mm) against S. aureous. So, it could be concluded that the antimicrobial (antibacterial) activity was found to be higher in apple peel than that of apple pomace. Moreover, the Gram's positive bacteria were found to be more susceptible to antibacterial potentials of apple peel and pomace, while Gram's negative bacteria showed relative resistance against extracts. From these results it was concluded that the food-borne pathogens and diseases can be controlled by the use of apple peel and pomace water-soluble extracts, which might be a cheaper and safe (natural) way of the treatment.

\section{Acknowledgements}

I am highly thankful to my research committee for their intellectual and technical guidance.

\section{Conflict of interest}

Authors has no conflict of interest.

\section{References}

1. Mojab F, Poursaeed M, Mehrgan H, Pakdaman S (2008) Antibacterial activity of Thymus daenensis methanolic extract. Pak J Pharm Sci 21(3): 210-213. 
2. Hancock EW (2005) Mechanisms of action of newer antibiotics for Gram-positive pathogens. Lancet Infect Dis 5(4): 209-218.

3. Nagesh KS, Shanthamma C (2009) Antibacterial activity of Curculigo orchioides rhizome extract on pathogenic bacteria. African Journal of Microbiology Research 3(1): 005-009.

4. Jayaprakasha GK, Selvi T, Sakariah KK (2003) Antibacterial and antioxidant activities of grape (Vitis vinifera) seed extracts. Food Research International 36(2): 117-122.

5. Singh RP, Murthy KNC, Jayaprakasha GK (2002) Studies on the antioxidant activity of pomegranate (Punica granatum) peel and seed extracts using in vitro models. J Agric Food Chem 50(1): 81-86.

6. Kabuki T, Nakajima H, Arai M, Ueda S, Kuwabara Y, et al. (2000) Characterization of novel antimicrobial compounds from mango (Mangifera indica L) kernel seeds. Food Chemistry 71(1): 61-66.

7. Prasad KN, Xie H, Hao J, Yang B, Qiu S, et al. (2010) Antioxidant and anticancer activities of 8 - hydroxypsoralen isolated from wampee (Clausena lansium Lour. Skeels) peel. Food Chemistry 118(1): 62-66.

8. Kaneria M, Baravalia Y, Vaghasiya Y, Chanda S (2009) Determination of antibacterial and antioxidant potential of some medicinal plants from Saurashtra region, India. Indian J Pharm Sci 71(4): 406-412.

9. Boyer J, Liu R (2004) Apple phytochemicals and their health benefits. Journal of Nutrition 3: 5.

10. Potter D, Eriksson T, Evans RC, Oh SH, Smedmark JEE, et al. (2007) Phylogeny and classification of Rosaceae. Plant Systematics and Evolution 266(1-2): 5-43.

11. Pastene E, Speisky H, Troncoso M, Alarcon J, Figueroa G (2009) In vitro inhibitory effect of apple peel extract on the growth of Helicobacter pylori and respiratory burst induced on human neutrophils. J Agric Food Chem 57(17): 7743-7749.

12. Suarez B, Alvarez AL, Garcia YD, Barrio G, Lobo AP, et al. (2010) Phenolic profiles, antioxidant activity and in vitro antiviral properties of apple pomace. Food Chemistry 120(1): 339-342.

13. Garcia YD, Valles BS, Lobo AP (2009) Phenolic and antioxidant composition of by-products from the cider industry: Apple pomace. Food Chemistry 117(4): 731-738.

14. Zessner H, Pan L, Will F, Klimo K, Knauft J, et al. (2008) Fractionation of polyphenol enriched apple juice extracts to identify constituents with cancer chemopreventive potential. Mol Nutr Food Res 52(Suppl 1): 128144.

15. Rupasinghe HPV (2003) Using change for success: Fruit-based bioproduct research at the Nova Scotia Agricultural College. Annual Report 2003 of the Nova Scotia Fruit Growers Association 66-69.

16. Bhushan S, Kalia K, Sharma M, Singh B, Ahuja PS (2008) Processing of apple pomace for bioactive molecules. Crit Rev Biotechnol 28(4): 285296.

17. Alberto MR, Gómez Cordovés C, Manca De Nadra MC (2004) Metabolism of gallic acid and catechin by Lactobacillus hilgardii from wine. J Agric Food Chem 52(21): 6465-6469.

18. Malaviya A, Mishra N (2011) Antimicrobial activity of tropical fruits. International Journal of Biology 3(1): 1-4.
19. Muthuswamy, Rupasinghe HPV (2007) Fruit phenolics as natural antimicrobial agents: Selective antimicrobial activity of catechin, chlorogenic acid and phloridzin. Journal of food agriculture \& environment 5(3-4): 81-85.

20. Jelodarian S, Ebrahimabadi AH, Kashi JF (2013) Evaluation of antimicrobial activity of Malus domestica fruit extract from Kashan area. Avicenna J Phytomed 3(1): 1-6.

21. Sadeghian A, Ghorbani A, Mohamadi Nejad A, Rakhshandeh H (2011) Antimicrobial activity of aqueous and methanolic extracts of pomegranate fruit skin. Avicenna Journal of Phytomedicine 1(2): 67-73.

22. Spigno G, Tramelli L, De Faveri DM (2007) Effects of extraction time, temperature and solvent on concentration and antioxidant activity of grape marc phenolics. Journal of Food Engineering 81(1): 200-208.

23. Dent M, Dragović Uzelac V, Penic M, Brncic M, Bosiljkov T, et al. (2013) The effect of extraction solvents, temperature and time on the composition and mass fraction of polyphenols of dalmatian wild sage (Salvia officinalis L.) Extracts. Food Technology and Biotechnology 51(1): 84-91.

24. Hiba N, Rajha Darra EN, Vorobiev E, Louka N, Richard G, et al. (2013) An environment friendly, low-cost extraction process of phenolic compounds from grape Byproducts. Optimization by multi-response surface methodology. Food and Nutrition Science 4(6): 650-659.

25. Pinelo M, Rubilar M, Sineiro J, Nunez MJ (2004) Extraction of antioxidant phenolics from almond hulls (Prunus Amygdalus) and pine sawdust (Pinus pinaster). Food Chemistry 85(2): 267-273.

26. Wissam Z, Ghada B, Wassim A, Warid K (2012) Effective extraction of polyphenols and proanthocyanidins from pomegranate's peel. International Journal of Pharmacy and Pharmaceutical Sciences 4(suppl 3): 675-682.

27. Muralidhar RV, Chirumamila RR, Marchant R, Nigam P (2001) A response surface approach for the comparison of lipase production by Candida cylindracea using two different carbon sources. Biochemical Engineering Journal 9(1): 17-23.

28. Kelmanson JE, Jager AK, Van SJ (2000) Zulu medicinal plants with antibacterial activity. J Ethnopharmacol 69(3): 241-246.

29. Parikh P, McDaniel MC, Ashen MD, Miller JI, Sorrentino M, et al. (2005) Diets and cardiovascular disease. An evidence-based assessment. J Am Coll Cardiol 45(9): 1379-1387.

30. Holley AR, Patel D (2005) Improvement in shelf-life and safety of perishable foods by plant essential oils and smoke antimicrobials. Food Microbiology 22: 273-292.

31. Fratianni F, Sada A, Cipriano L, Masucci A, Nazzaro F (2007) Biochemical characteristics, antimicrobial and mutagenic activity in organically and conventionally produced Malus domestica, Annurca. The Open Food Science Journal 1: 10-16.

32. Jeong MR, Kim HY, Jeong Dan CJD (2009) Antimicrobial activity of methanol extract from Ficus carica leaves against oral bacteria. Journal of Bacteriology and Virology 39(2): 97-102.

33. Balakrishnan N, Bhaskar VH, Jayakar B, Sangameswaran B (2006) Short communication antibacterial activity of Mimosa pudica, Aegle marmelos and Sida carlifolia. Pharmcognosy Magazine 2(7): 198-199. 